International

Medical Society

http://imedicalsociety.org

\title{
Sensitive Damage in Leprosy: a Longitudinal and Retrospective Study
}

\section{Amanda Teixeira Labelle Castanheira ${ }^{1}$, Sabrina Sampaio Bandeira2, Alianne Violet Alves Chichester ${ }^{1}$ Ana Luísa Mendes dos Reis ${ }^{1}$, Carlos Victor da Silva Nascimento ${ }^{1}$ Caroline da Silva Alves Palheta ${ }^{1}$, Walter Refkalefsky Loureiro ${ }^{1}$, Francisca Regina Oliveira Carneiro ${ }^{1}$, Carla Andréa Avelar Pires ${ }^{1}$}

\section{Abstract}

Background: The evaluation of leprosy patients requires a careful dermatological and neurological examinationin order to monitor the possible damage to the peripheral nerves. This study focused on evaluate the sensitivity at the time of diagnosis and discharge of leprosy patients from Dermatology Department of the State University of the State of Pará.

Methods and Findings: is a longitudinal, retrospective and descriptive study based on medical records that presented neurological assessment and degree of physical disabilityof 30 patients assisted at a referral service between 2016 and 2019, applying descriptive statistical analysis. Concerning neural involvement, $88.89 \%$ of the patients with neural damage were male, $100 \%$ of patients in this group were multibacillary ( $p$-value: 0.02 ), 42.8\% were borderliners ( $p$-value: 0.04 ), $88.8 \%$ had some type of leprosy reaction ( $p$-value: 0.02 ) and $44.4 \%$ of the patients had a diagnosis of leprosy with more than one year of disease evolution; most patients with neural involvement $(N=16)$ had more than one nerve affected, with the right tibial nerve being the most affected (24.14\%); It was noted that a considerable portion of multibacillary patients did not improve or worsened (75\%), and the borderline form was the one with the worst prognosis, showing 50\% of patients did not respond to treatment.
1 Universidade do Estado do Pará, Belém, Pará, Brazil.

2 Unidade de Referência em Dermatologia Sanitária Marcello Cândia, Marituba, Pará, Brazil.

Contact information:

Carlos Victor da Silva Nascimento.

Address: Universidade do Estado do Pará. Travessa Perebebuí, n²623, Belém. 66095-450, Brazil.

Tel: +5591980439291 .

झ cvuepa@gmail.com 
Conclusions: Therefore, most of the patients with neural damage were multibacillary, and borderliners, with many of those without presenting improvement, or showing worsening of clinical condition after multidrug therapy. Thus, it is highlighted the primary role of longitudinal assessment of those patients, in view of the possibility of chronification and sequel development.

\section{Keywords}

Dermatology; Leprosy;

Sensivity; Public Health.

\section{Introduction}

Leprosy is a chronic, infectious disease, whose etiological agent is the Mycobacterium lepraebacillus, which presents high infectivity and low pathogenicity [1]. Worldwide, in 2018, 208,619 new cases were detected, of which 30,957 were in the Americas. It is noteworthy that among the total number of new cases globally, three countries (Brazil, India and Indonesia) accounted for $79.6 \%$ of patients notified to the World Health Organization (WHO). [2]

Brazil, specifically, registered 28,660 new cases in 2018 , representing $93 \%$ of the incidence of the disease in the Americas, and, between 2014 and 2018, 2,109 new cases of patients with grade 2 disability. In the State of Pará, there are almost 30 patients per 100 thousand inhabitants. In 2018, the State had a new case detection rate of 30.23 per 100,000 inhabitants, 23.37 new cases of disability for 1 million inhabitants. Therefore, the State is considered with high risk for acquiring the disease. $[3,4]$

According to the Madrid classification, clinically, leprosy is categorized according to the appearance, amount, and severity of the lesions into: undetermined, tuberculoid, borderline, and virchowian (lepromatous). [5] Two stable and opposite poles (virchowian and tuberculoid) and two unstable groups (undetermined and borderline), which would move towards one of the poles, are considered in the natural evolution of the disease [6]. The Brazilian Ministry of Health (MH) also makes use of the ope- rational classification, which is based on the number of cutaneous lesions: paucibacillary (up to five lesions) and multibacillary (more than 5 lesions). [1]

According to $\mathrm{MH}$, all leprosy cases, regardless of clinical form, should receive neurological assessment and disability assessment at the time of diagnosis, and at least once in half of treatment, and also at discharge for cure. All attention should be given to early diagnosis, including neural impairment [4]. The neurological examination allows the diagnosis and early therapeutic intervention of neuritis, in order not to allow the evolution to physical disabilities, as well as to follow up the evolution of the disease.

For the diagnosis of leprosy is primordial to understand the clinical and epidemiological features of this disease. To make this possible, it's essential and mandatory to evaluate the communicants of each index case, as well as the analysis of personal and family history of leprosy and other comorbidities, the life conditions of individuals affected, as well as the dermatological andneurological exam, in order to monitor the possible damage to the peripheral nerves (sensory, motor, and / or autonomous). [7]

It is noteworthy that the neurological assessment, which is part of the clinical examination, as well as the assessment of the patient's occupation, daily activities and complaints, are indispensable in the diagnosis and prevention of physical disabilities. Among the neurological evaluation stages, the 
sensitivity evaluation is very important to avoid the physical disabilities, as the decrease and/or loss of the hands and feet sensitivity can lead the patient to develop ulcers, infections, reabsorption and even amputations, especially in endemic areas such as Brazil. [2, 7]

\section{Methods}

This is a longitudinal, retrospective and descriptive study based on medical records that presented neurological assessment and degree of physical disability, according to the recommendations of the $\mathrm{MH}$ [8]. The sample consisted of 30 patients diagnosed with leprosy, treated at the Dermatology Department of the State University of Pará, who started and were discharged from multidrug therapy (MDT) between January 2016 to July 2019, with or without leprosy reactions, of both sexes and all age groups. The study was approved by the UEPA Research Ethics Committee on March 28, 2017, Opinion number: 1.986.379, and the free and informed consent form was signed by the participating patients.

Social and demographic information and the clinical form of leprosy were collected from medical records according to the operational classification [8] and the Madrid classification [9]. From the neurological evaluation form, the sensitivity of the hands and feet were assessed at the time of diagnosis and at the time of discharge from multidrug therapy.

Sensitivity was assessed using the Semmes-Weinstein Monofilament Set (6 monofilaments: $0.05 \mathrm{~g}$, $0.2 \mathrm{~g}, 2 \mathrm{~g}, 4 \mathrm{~g}, 10 \mathrm{~g}$ and $300 \mathrm{~g}$ ) at the hand and foot sensitivity assessment points standardized by the Simplified Neurological Assessment form from $\mathrm{MH}$. Each monofilament is related to a specific pressure force to bend it as it is applied to the skin, representing a functional level. [9]

In the interpretation of the sensory evaluation with the monofilaments, the following functional levels were considered: the sensitivity of the hands and feet were considered preserved when there was tactile perception by the individual of the green monofilament $(0.05 \mathrm{~g})$, and decreased in the hand and normal in the foot when there was a perception of blue monofilament $(0.2 \mathrm{~g})$. The perception of violet monofilament $(2 \mathrm{~g})$ is characterized by decreased protective sensitivity in the hands and sometimes in the feet. From the perception of only the red $(4 \mathrm{~g})$ onwards, orange (10g), pink / magenta red $(300 \mathrm{~g})$ monofilament, the loss of protective sensitivity in the hands and feet was characterized.

When comparing the sensory assessment of the diagnosis with the sensory assessment of discharge, the worsening or improvement of the condition was considered. Interpretation of improvement or worsening of sensitivity was considered when there was an improvement or worsening of the two-point functional level in the nerve pathway compared to the previous assessment, or improvement or worsening of two or more monofilament functional levels in only one point of the nervous pathway (example: evolution from violet to orange monofilament). [10]

It is worth noting again that the protective sensitivity in the hands and / or feet was considered altered when individuals did not feel the $2 \mathrm{~g}$ filament (violet filament), alteration by which they became more vulnerable to trauma, with the inability to perceive harmful stimuli to the skin.

The sample was analyzed by descriptive statistics, using measures of central tendency (arithmetic mean), variance (standard deviation) and absolute and relative frequencies. For the total categorical evaluation of the sample we used the chi-square test of adherence and for evaluation between groups we used the $G$ test. All statistical inference was performed using BioEstat 5.4 software, considering a significant $p$-value $\leq 0.05$.

\section{Results}

A total of 30 patients $(n=30)$ were evaluated, most of them (30\%) from $46-60$ years old, with a mean 
age of 42.6 years. There was no gender difference, as there were 15 female patients (50\%) and 15 male patients $(50 \%)$, mostly from the metropolitan region of Belém (80\%).

Regarding the operational classification, $66.6 \%$ of the patients $(n=20)$ were multibacillary and $53.3 \%$ $(n=16)$ were classified with the borderline clinical form (Madrid classification). In addition, 53.3\% of patients $(n=16)$ had leprosy reaction. About the diagnosis time, $46.6 \%$ of patients were diagnosed after 1 year of symptoms $(n=14)$ (Table 1$)$.

Concerning neural involvement, $88.89 \%$ of the patients with neural damage were male. Among the total universe of patients with neural injury, $77.77 \%$ of the patients were older than 45 years and came from the metropolitan region of Belém (Table 1).

Still in patients with peripheral nerve involvement, $100 \%$ of patients in this group were multibacillary ( $p$-value: 0.02$), 42.8 \%$ were borderliners ( $p$-value: $0.04), 88.8 \%$ had some type of leprosy reaction ( $p$-value: 0.02 ) and $44.4 \%$ of the patients had a diagnosis of leprosy with more than one year of disease evolution (Table 1).

Regarding the number and type of nerve affected, most patients with neural involvement $(N=16)$ had more than one nerve affected, with the right tibial nerve being the most affected (24.14\%) (Table 2). This data corroborates the main complaints of the patients, considering that among the patients with symptomatic neuritis, most presented symptoms related to the left and right tibial nerves (25\% in each), as shown on Table 3.

However, among patients with silent neuritis, that is, who had no complaints related to neural damage, but presented alterations on physical examination, the involvement presented a distinct profile. In this group, besides the lesion of the right tibial nerve $(23.08 \%)$, which was also the most affected in the other patients, there was also an important involvement of the left ulnar nerve $(23.08 \%)$, as shown in Table 4.
Table 1. Sociodemographic characteristics and clinical aspects of leprosy patients, according to presence and absence of affected nerve, Belém, Pará, 2019.

\begin{tabular}{|c|c|c|c|c|c|}
\hline \multirow[t]{2}{*}{ Variable } & \multicolumn{2}{|c|}{$\begin{array}{l}\text { Affected } \\
\text { nerve }\end{array}$} & \multicolumn{2}{|c|}{$\begin{array}{c}\text { Without } \\
\text { affected nerve }\end{array}$} & \multirow{2}{*}{$\begin{array}{c}\begin{array}{c}p \\
\text { value }\end{array} \\
\text { G Test }\end{array}$} \\
\hline & $n$ & $\%$ & $n$ & $\%$ & \\
\hline \multicolumn{6}{|c|}{ Sociodemographic characteristics } \\
\hline \multicolumn{6}{|l|}{ Age Group } \\
\hline 19 to 25 years & 1 & 11.11 & 6 & 28.57 & \multirow{5}{*}{0.4022} \\
\hline 26 to 45 years & 1 & 11.11 & 6 & 28.57 & \\
\hline 46 to 60 years & 4 & 44.44 & 5 & 23.81 & \\
\hline$>60$ years & 3 & 33.33 & 4 & 19.05 & \\
\hline Total & 9 & 100.00 & 21 & 100.00 & \\
\hline \multicolumn{6}{|l|}{ Sex } \\
\hline Male & 8 & 88.89 & 7 & 33.33 & \multirow{3}{*}{0.0135} \\
\hline Female & 1 & 11.11 & 14 & 66.67 & \\
\hline Total & 9 & 100.00 & 21 & 100.00 & \\
\hline \multicolumn{6}{|l|}{ Origin } \\
\hline $\begin{array}{l}\text { Metropolitan } \\
\text { Region of Belém }\end{array}$ & 7 & 77.78 & 17 & 80.95 & \multirow{3}{*}{0.7620} \\
\hline Other Cities & 2 & 22.22 & 4 & 19.05 & \\
\hline Total & 9 & 100.00 & 21 & 100.00 & \\
\hline \multicolumn{6}{|c|}{ Clinical Aspects } \\
\hline \multicolumn{6}{|c|}{ Operational classification } \\
\hline Multibacillary & 9 & 100.00 & 11 & 52.38 & \multirow{3}{*}{0.0201} \\
\hline Paucibacillary & - & - & 10 & 47.62 & \\
\hline Total & 9 & 100.00 & 21 & 100.00 & \\
\hline \multicolumn{6}{|l|}{ Leprosy Reaction } \\
\hline Yes & 8 & 88.89 & 8 & 38.10 & \multirow{3}{*}{0.0254} \\
\hline No & 1 & 11.11 & 13 & 61.90 & \\
\hline Total & 9 & 100.00 & 21 & 100.00 & \\
\hline \multicolumn{6}{|c|}{ Madrid Clinical Form } \\
\hline Virchowian & 2 & 22.22 & 2 & 9.52 & \multirow{5}{*}{0.0458} \\
\hline Borderline & 7 & 77.78 & 9 & 42.86 & \\
\hline Tuberculoid & - & - & 6 & 28.57 & \\
\hline Undetermined & - & - & 4 & 19,05 & \\
\hline Total & 9 & 100.00 & 21 & 100.00 & \\
\hline \multicolumn{6}{|l|}{ Diagnosis Time } \\
\hline$<6$ months & 1 & 11.11 & 5 & 23.81 & \multirow{4}{*}{0.6240} \\
\hline 6 months - 1 year & 4 & 44.44 & 6 & 28.57 & \\
\hline$>1$ year & 4 & 44.44 & 10 & 47.62 & \\
\hline Total & 9 & 100.00 & 21 & 100.00 & \\
\hline
\end{tabular}


Table 2. Description of nerve type (among those affected) in leprosy patients, Belém, Pará, 2019.

\begin{tabular}{|l|c|c|c|}
\hline \multicolumn{1}{|c|}{ Affectednerve } & $\mathbf{n}$ & $\%$ & p-value \\
\hline Right median & 4 & 13.79 & \\
\hline Left median & 4 & 13.79 & \\
\hline Right tibial & 7 & 24.14 & \\
\hline Left tibial & 5 & 17.24 & Doesn't \\
\hline Right ulnar & 4 & 13.79 & Apply \\
\hline Left ulnar & 5 & 17.24 & \\
\hline Total & 29 & 100.00 & \\
\hline
\end{tabular}

Table 3. Neural damage according to nerve type among leprosy patients who presented symptoms during diagnosis, Belém, Pará, 2019.

\begin{tabular}{|l|c|c|c|c|c|}
\hline \multirow{2}{*}{$\begin{array}{c}\text { Nerve path } \\
\text { with complaint }\end{array}$} & \multicolumn{2}{|c|}{$\begin{array}{c}\text { Affected } \\
\text { nerve }\end{array}$} & \multicolumn{2}{c|}{$\begin{array}{c}\text { Not affected } \\
\text { nerve }\end{array}$} & $\begin{array}{c}\text { p } \\
\text { value }\end{array}$ \\
\cline { 2 - 6 } & $\mathrm{n}$ & $\%$ & $\mathrm{n}$ & $\%$ & G Test \\
\hline Right median & 2 & 12.50 & 4 & 20.00 & \\
Left median & 2 & 12.50 & 4 & 20.00 & \\
\hline Right tibial & 4 & 25.00 & 2 & 10.00 & \\
Left tibial & 4 & 25.00 & 2 & 10.00 & 0.6530 \\
Right ulnar & 2 & 12.50 & 4 & 20.00 & \\
\hline Left ulnar & 2 & 12.50 & 4 & 20.00 & \\
\hline Total & 16 & 100.00 & 20 & 100.00 & \\
\hline & \multicolumn{5}{|c|}{ Source: Research protocol, 2019. }
\end{tabular}

Table 4. Neural damage according to affected nerve, among leprosy patients who had no complaints during the diagnosis.Belém, Pará, 2019.

\begin{tabular}{|l|c|c|c|c|c|}
\hline \multicolumn{1}{c|}{$\begin{array}{c}\text { Nerve path } \\
\text { without } \\
\text { complaint }\end{array}$} & \multicolumn{2}{|c|}{$\begin{array}{c}\text { Affected } \\
\text { nerve }\end{array}$} & \multicolumn{2}{c|}{$\begin{array}{c}\text { Not affected } \\
\text { nerve }\end{array}$} & $\begin{array}{c}\text { p } \\
\text { value }\end{array}$ \\
\cline { 2 - 6 } & $\mathrm{n}$ & $\%$ & $\mathrm{n}$ & $\%$ & G Test \\
\hline Right median & 2 & 15.38 & 22 & 16.79 & \\
Left median & 2 & 15.38 & 22 & 16.79 & \\
\hline Right tibial & 3 & 23.08 & 21 & 16.03 & \\
Left tibial & 1 & 7.69 & 23 & 17.56 & 0.9242 \\
\hline Right ulnar & 2 & 15.38 & 22 & 16.79 & \\
\hline Left ulnar & 3 & 23.08 & 21 & 16.03 & \\
\hline Total & 13 & 100.00 & 131 & 100.00 & \\
\hline & \multicolumn{5}{|c|}{ Source: Research protocol, 2019. } \\
\hline
\end{tabular}

Regarding the clinical evolution of patients with neural damage, there was a $43.75 \%$ reduction in patients' complaints when comparing reports of admission and discharge, being the right median nerves and both tibial nerves (all representing 22.22\% each), the most refractory to treatment, as shown in Table 5.

Table 5. Complaints of patients with affected nerve $(n=9)$ during diagnosis and after discharge, Belém, Pará, 2019.

\begin{tabular}{|l|c|r|r|r|r|}
\hline $\begin{array}{l}\text { Nerve } \\
\text { Right }\end{array}$ & Admission & $\%$ & Discharge & $\%$ & p-value \\
\hline $\begin{array}{l}\text { median } \\
\text { Left } \\
\text { median }\end{array}$ & 2 & 12.50 & 1 & 11.11 & \\
$\begin{array}{l}\text { Right } \\
\text { tibial } \\
\text { Left }\end{array}$ & 3 & 18.75 & 2 & 22.22 & 0.9998 \\
\hline $\begin{array}{l}\text { tibial } \\
\text { Right } \\
\text { ulnar }\end{array}$ & 3 & 18.75 & 2 & 22.22 & \\
\hline $\begin{array}{l}\text { Left } \\
\text { ulnar }\end{array}$ & 2 & 12.50 & 1 & 11.11 & \\
\hline Total & 16 & 100.00 & 9 & 100.00 & \\
\hline & & Source: Research protocol, 2019. \\
\hline
\end{tabular}

By assessing the evolution of the neural injury, it was noted that a considerable portion of multibacillary patients did not improve or worsened (75\%), and the borderline form was the one with the worst prognosis, showing $50 \%$ of patients did not respond to treatment, and evolved with maintenance or worsening of the condition, as well as $50 \%$ of patients with leprosy reaction as shown in Table $\mathbf{6}$.

However, patients with left ulnar nerve involvement had a different evolution from the other patients. Patients with treatment refractoriness were mostly from the non-borderline group (51.85\%), but still within the multibacillary group, with $62.96 \%$. Another differential of this group was that the majority $(51.85 \%)$ of the patients, among those who did not improve after MDT, did not present a leprosy reaction, as shown in Table 7. 
Table 6. Evolution of the median, tibial (right and left) and right ulnar nerves of patients diagnosed with leprosy, Belém, Pará, 2019.

\begin{tabular}{|l|c|c|c|c|c|}
\hline \multirow{2}{*}{ Variable } & \multicolumn{4}{|c|}{ Improved } & \multicolumn{2}{c|}{$\begin{array}{c}\text { Worsened/ } \\
\text { Didn't improve }\end{array}$} & $\begin{array}{c}\text { p } \\
\text { value }\end{array}$ \\
\cline { 2 - 6 } & $n$ & $\%$ & $n$ & $\%$ & G Test \\
\hline ClinicalForm & & & & & \\
\hline Borderline & 2 & 100.00 & 14 & 50.00 & \\
\hline Non-Borderline & - & - & 14 & 50.00 & 0.5142 \\
\hline Total & 2 & 100.00 & 28 & 100.00 & \\
\hline OperationalClassification & & & & \\
\hline Multibacillary & 2 & 100.00 & 18 & 75.00 & \\
\hline Paucibacillary & - & - & 10 & 25.00 & 0.7912 \\
\hline Total & 2 & 100.00 & 24 & 100.00 & \\
\hline Reaction & & & & & \\
\hline Yes & 2 & 100.00 & 14 & 50.00 & \\
\hline No & - & - & 14 & 50.00 & 0.5142 \\
\hline Total & 2 & 100.00 & 28 & 100.00 & \\
\hline & & Source: & Research protocol, 2019. \\
\hline
\end{tabular}

Table 7. Evolution of the left ulnar nerve in patients diagnosed with leprosy, Belém, Pará, 2019.

\begin{tabular}{|c|c|c|c|c|c|}
\hline \multirow[t]{2}{*}{ Variable } & \multicolumn{2}{|c|}{ Improved } & \multicolumn{2}{|c|}{$\begin{array}{c}\text { Worsened/ } \\
\text { Didn't improve }\end{array}$} & \multirow{2}{*}{$\begin{array}{c}\mathbf{p} \\
\text { value } \\
\text { G Test }\end{array}$} \\
\hline & $\mathrm{n}$ & $\%$ & $n$ & $\%$ & \\
\hline \multicolumn{6}{|l|}{ ClinicalForm } \\
\hline Borderline & 3 & 3 & 13 & 48.15 & \multirow{3}{*}{0.2502} \\
\hline Non-Borderline & - & - & 14 & 51.85 & \\
\hline Total & 3 & 100.00 & 27 & 100.00 & \\
\hline \multicolumn{6}{|c|}{ OperationalClassification } \\
\hline Multibacillary & 3 & 3 & 17 & 62.96 & \multirow{3}{*}{0.4958} \\
\hline Paucibacillary & - & - & 10 & 37.04 & \\
\hline Total & 3 & 100.00 & 27 & 100.00 & \\
\hline \multicolumn{6}{|l|}{ Reaction } \\
\hline Yes & 3 & 3 & 13 & 48.15 & \multirow{3}{*}{0.2502} \\
\hline No & - & - & 14 & 51.85 & \\
\hline Total & 3 & 100.00 & 27 & 100.00 & \\
\hline
\end{tabular}

Source: Research protocol, 2019.

\section{Discussion}

Leprosy is a highly prevalent disease in the country, Brazil being considered by the WHO (World Health Organization) one of the 23 countries with the highest prevalence in the world, and the main responsible for cases in Latin America [2]. Given its high disabling potential, which can lead to physical deformities, functional limitation and socio-emotional impairment, as well as its high prevalence in the economically active population, such disease requires early detection and treatment with emphasis on the prevention of sensory changes that precede permanent deformities. [1]

In the present study, the prevalence of neural damage found was mostly in male patients (88.8\%), aged 46 to 60 years (44.4\%). Such data reinforce the finding by Santana et al. (2018), in whose study it was found that $58.7 \%$ of the patients were male, considering that this population, especially on economically active age, are the most likely to evolve with nerve trunk injuries. This is due, mostly, to the resistance of this group to treatment and to the physician's search, leading to a late diagnosis. Thus, the risk of developing multibacillary forms and, consequently, neural lesions increases exponentially, which generally does not occur in female patients [11].

In addition, another important sociodemographic factor was the higher prevalence of neural injury in patients from the Belém metropolitan region (77.8\%), compared to patients from the interior of the state. This high number demonstrates the role of large urban agglomerations in the greater spread of the disease, due in large part to the marginalization of the population, with increased social vulnerability situations and difficulty in accessing health services, leading to a late detection of leprosy, many already with sequelae [12].

Regarding clinical form, based on operational classification, $100 \%$ of patients with neural damage were multibacillary, which is in line with the worldwide literature, where multibacillary patients are the most susceptible to developing neurological lesions. [13]

Another important finding was the high prevalence of patients classified as borderliners (77.7\%) 
evolving with neural injury, demonstrating not only the high prevalence of this clinical form in the state of Pará, as Pires et al. [14] as well as the increased risk of this clinical form of the disease for the development of neural damage. [13]

In addition, it was found that $88.8 \%$ of patients with nerve injury had some type of leprosy reaction. The reverse reaction, or type 1, is directly related to the borderline and virchowian forms, besides being the main cause of neural damage in such patients and, consequently, has a high disability potential of this group, being present in about $30 \%$ of the patients as assessed by Save et al. [15]. This complication of leprosy can occur even years after the completion of MDT, being considered a dermatological urgency, which should be remedied as quickly as possible. [16]

Regarding the type of nerve affected in patients, at the moment of admission, the main involvement was in the tibial nerves (right and left), which accounted for $41.3 \%$ of the affected nerve trunks. This finding shows a high potential for damage to patients, considering that neural damage in these nerves is directly related to the formation of plantar ulcers, with subsequent evolution to grade 2 disability. [17]

This finding is especially true in the male population, which was the most affected group in the present study. Moreover, this population in general, besides being economically active, has, in particular, work activities with potential risk of damage to the plantar region, which may lead to permanent labor disabilities and future financial dependence of these patients from the State, such as was observed by Reyila et al. [16], which reinforces the need for early diagnosis and treatment, helping to reduce public spending through disease prevention and disability.

When comparing the affected nerves in symptomatic patients with asymptomatic patients, the first group presented mostly damage to the tibial nerves (50\%). In the second group, involvement was found mainly in the left ulnar nerve (23\%) and right tibial nerve $(23 \%)$.

The difference found demonstrates the importance of detailed neurological examination, even in asymptomatic patients, given the insidious character of the disease and the possible cases of silent neuritis, defined by neurological impairment with progressive and insidious functional impairment in the absence of clinical symptoms reported by the patient. This clinical condition may lead to limitation of work activities, in addition to the possible development of chronic neuropathic pain, which may be present in up to $29 \%$ of patients up to 10 years after treatment in cases of late diagnosis, as observed by Saunderson et al. [18, 19]

Regarding the evolution of patients throughout treatment, a reduction of $43.7 \%$ in complaints was observed when comparing diagnosis versus discharge. However, with the physical examination, it was found that among the multibacillary patients, $75 \%$ of patients did not improve or even worsened after multidrug therapy (MDT). Among these, the borderline form was the one with the worst prognosis, with $50 \%$ of patients showing no improvement, and $50 \%$ also evolved with leprosy reaction.

These data demonstrate the spectrum of a possible leprosy chronification, raising the need for longitudinal follow-up, even after the completion of MDT. In the study by Save et al. (2016) it was found the presence of viable $\mathrm{M}$. leprae in reaction lesions in $76 \%$ of patients with type 1 reactions. Another important finding found in the same study was the presence of bacillary viability in reactions especially in the borderline group, which was most affected in the present study, reinforcing the need for greater attention to such patients. [15]

In a study by Raposo et al. [17] with a Brazilian population, $17.1 \%$ of patients progressed to grade 2 disability after MDT. It is worth noting that this study also found a strong relationship between the evolution to disability with multibacillary forms, as 
well as the correlation between disease chronicity and the presence of leprosy reactions, in agreement with the data found in the present study. [20]

Moreover, among the group of patients with involvement of the right tibial and ulnar nerves, 50\% of patients who did not improve after MDT evolved with leprosy reaction. This observation demonstrates what had already been observed by Kamath et al. (2014) [16], who states that reactions play an important role in the chronicity of Hansen's disease and is another reason for long-term follow-up of these patients.

However, the group of patients with left ulnar nerve involvement showed a different evolution, with $51.8 \%$ of patients refractory to treatment being within the non-borderline group. In addition, most patients with such an affected nerve did not present a leprosy reaction, with $51.8 \%$ of the patients not presenting this complication.

The involvement of this nervous site can have a great impact on patients' quality of life, considering the possibility of developing fixed-claw deformity [21]. In addition, the observed data demonstrate the role of high bacillary burden with possible nontreatment-responsive sequelae, which are directly related to the host response to Hansen's bacillus. In this process, the main pathogenic pathway concerns neural growth factor (NGF), which is fundamental in the restoration of the affected peripheral nerves, and which is generally inhibited by the antibodymediated immune response in multibacillary forms. [22]

However, it is essential to understand that the data found in the present study cannot be expanded to the general population, due to the small sample size analyzed, as well as the consideration of a single dermatology service. Therefore, further and broader studies should be encouraged to better understand sensory damage in leprosy patients nationally and globally.

\section{Conclusions}

Therefore, most of the patients with neural damage were multibacillary, and borderliners, with many of those without presenting improvement, or showing worsening of clinical condition after multidrug therapy. Thus, it is highlighted the primary role of longitudinal assessment of those patients, in view of the possibility of chronification and sequel development.

\section{Fundings}

The authors declare having had no financial support.

\section{Conflict of interest disclosures}

The authors declare that there are no conflicts of interest in this study.

\section{References}

1. Brasil. Ministério da Saúde. Secretaria de Vigilância em Saúde. Coordenação-Geral de Desenvolvimento da Epidemiologia em Serviços. Guia de Vigilancia em Saude. Volume único.3 edição. Brasilia: Brasil; 2019. pagina 294-296

2. World Health Organization (2019). Global leprosy update, 2018: moving towards a leprosy-free world Weekly Epidemiological Record. (2019); 94 (35/36), 389 - 411. World Health Organization.

3. Hanseníase -DATASUS- Indicadores epidemiológicos e operacionais de hanseníase, por ano diagnóstico -Municípios/ UF/Regiões/ Brasil-2018. Brasil: Ministério da Saúde. Available from: http://tabnet.datasus.gov.br/cgi/sinannetbd/hanseniase/ hansDB2018.html

4. Brasil. Ministério da Saúde. Situação epidemiológica e estratégias de prevenção, controle e eliminação das doenças tropicais negligenciadas no Brasil, 1995 a 2016. Brasilia, Distrito Federal, 2018: Carmelita Ribeiro Filha (Editora científica), p.8. Available from: http://portalarquivos2.saude.gov.br/images/ pdf/2018/novembro/19/2018-032.pdf

5. Brasil. Ministério da saúde. Vigilância em Saúde: Dengue, Esquistossomose, Hanseníase, malaria, Tracoma e Tuberculose. Caderno de Atenção Básica. n. 21. 2 ed. rev. Brasília 2008: Secretaria de Atenção à Saúde.

6. lastoria JC, Abreu MAMM. Hanseníase: Diagnostico e Tratamento. Diagn Tratamento. 2012; 17(4):173-9. 
7. Palú FH, Cetolin SF. Perfil clinico epidemiológico dos pacientes com hanseníase no extremo-oeste catarinense, 2004 a 2014. Arq. Catarin Med. 2015 abr-jun; 44(2): 90-98.

8. Brasil. Ministério da Saúde. Secretaria de Vigilância em Saúde. Departamento de Vigilância das Doenças Transmissíveis. Guia prático sobre a hanseníase [recurso eletrônico] / Ministério da Saúde, Secretaria de Vigilância em Saúde, Departamento de Vigilância das Doenças Transmissíveis. - Brasília : Ministério da Saúde, 2017.

9. Basombrio, G. et al. Draft report of classification Committee. In: Congressolnternacional de Leprologia; 1953; Madrid: Associación Internacional de la Lepra; 1953. p. 75- 86.

10. Como reconhecer e tratar reações hansênicas. Secretaria do estado de saúde de Minas Gerais Superintendencia de atenção à saúde, diretoria de normalização e atenção a saúde, coordenadoria estadual de Dermatologia sanitária de Minas Gerais. Belo Horizonte, Minas gerais. 2005. Pagina 29-30

11. Santana EMF, Brito KKG, Antas EMVA, Nogueira JDA, Laedebal ODCP, Silva MA, et al. Original article. RevlnstMedTrop São Paulo. 2018; 60(21).

12. Souza CDF. Hanseníase e determinantes sociais da saúde: Uma abordagem a partir de métodos quantitativos- Bahia, 20012015. 2018. Tese (Doutorado em Saúde Pública)- Instituto Aggeu Magalhães, Fundação Oswaldo Cruz, Recife, 2018.

13. Silva JSR, Palmeira IP, Sá AMM, Nogueira LMV, Ferreira AMR. Variáveis clínicas associadas ao grau de incapacidade física na hanseníase. RevCuid. 2019; 10(1)

14. Pires $C A A$, Chaves EC, Salmen $C F$, Balieiro $A B$ da $R$, Santos $M B L$, de Araújo Filho GG, Mesquita FM, Bandeira SS, Xavier MB. Análise do perfil clínico- epidemiológico da hanseníase no Pará e avaliação dos indicadores de saúde. REAS [Internet]. jul.2019; (27):e899. Available from: https://acervomais.com.br/index.php/ saude/article/view/899

15. Save MP, Dighe AR, Natrajan M, et al. Association of viable Mycobacterium leprae with Type 1 reaction in leprosy. Lepr Rev 2016; 87: 78-92.

16. Kamath S, Vaccaro SA, Rea TH, Ochoa MT. reactions in leprosy. J Am Dermatology. 2014; 71(4):795-803.
17. Reyila VP, Betsy A, Riyaz N, Sasidharanpillai S, Veil P. Clinicoepidemiological study of disability due to leprosy at the time of diagnosis among patients attending a tertiary care institution. Indian J Dermatol. 2019; 64(2):106-11.

18. Saunderson P, Bizuneh E, Leekassa R. Neuropathic pain in people treated for multibacillary leprosy more than ten years previously. Lepr Rev. 2008; 79(3):270-6

19. Lockwood DNJ. Chronic aspects of leprosy-neglected but important. Trans R Soc Trop Med Hyg. 2019; 112(12):813-7.

20. Raposo MT, Reis MC, Caminha AVQ, Heukelbach J, Parker LA, Pastor-Valero M, et al. (2018) Grade 2 disabilities in leprosy patients from Brazil: Need for follow-up after completion of multidrug therapy. PLoS Negl Trop Dis 12(7): e0006645.

21. Santana EMF de, Brito KKG, Nogueira JDA, Leadebal ODCP, Costa MML, Silva MA da, et al. Deficiências e incapacidades na hanseníase: do diagnóstico à alta por cura. Rev Eletrônica Enferm. 2018; 20:1-11.

22. Aarão TL de, Sousa JR De, Falcão ASC, Falcão LFM, Quaresma JAS. Nerve Growth Factor and Pathogenesis of Leprosy: Review and Update. 2018; 9(May):1-8.

Publish in International Archives of Medicine

International Archives of Medicine is an open access journal publishing articles encompassing all aspects of medical science and clinical practice. IAM is considered a megajournal with independent sections on all areas of medicine. IAM is a really international journal with authors and board members from all around the world. 